\title{
Online forums: a tool to enhance experimental engineering laboratories
} Patricia Muñoz-Escalona ${ }^{1}$ and Andrew McLaren ${ }^{2}$

\section{Abstract}

Asynchronous discussion forums were implemented as an e-learning tool to enhance the teaching of principles in materials science for first year undergraduate students in the Department of Mechanical and Aerospace Engineering. Time in the laboratory is restricted and therefore only one experiment can be achieved in the class. Asynchronous discussion forums were used as means of enhancing content, extending student participation and facilitating student discussion subsequent to the laboratory session. From online feedback surveys, conducted at different stages throughout the class, results showed $60 \%$ of the students had never used online forums before, $96 \%$ of the students engaged in the activity and $80 \%$ of the students agreed that online forums are an alternative platform to use to discuss and compare results when time in the laboratory is restricted. The implementations of asynchronous discussion forums encouraged students to conduct deep learning in order to enhance the discussion thread they were involved.

Keywords: Asynchronous discussion forum, experimental laboratory, first year undergraduate, teaching, learning.

\footnotetext{
${ }^{1}$ School of Engineering and Computing, University of the West of Scotland, Paisley, UK

${ }^{2}$ Department of Mechanical \& Aerospace Engineering, University of Strathclyde, Glasgow, UK
} 


\section{Introduction}

Learning activities are used to allow learners to achieve a learning objective. Students learn and gain knowledge all the way through their undergraduate education, starting with basic or introductory concepts and progressing to deeper knowledge in their discipline as they move towards the final year. This process of learning can be summarized in the four stages of the Kolb's Learning Cycle which involves key aspects such as concrete experience, reflective observation, abstract conceptualization and active experimentation [1].

Marton and Säijo described two approaches for learning: surface learning and deep learning [2]. As the name implies, when using the surface approach learners do not fully comprehend the information, they only focus on disjointed facts, perhaps in order to pass a specific assessment. With the deep approach, learners develop understanding and interpret the meaning of the concepts by digging below the surface, enabling them to subsequently solve complex problems.

There are different types of activities that can be incorporated in the learning process and there are over 2000 e-learning tools which can be applied when teaching and learning online [3]. Among these are: tools created to track learning outcomes (e.g. quizzes); tools used for delivering live meetings (e.g. webinars); tools used for communication activities (e.g. discussion forums, newsletters). Observed media, technology and process are the bases of e-learning activities. They are spreading around the world, providing the opportunity to interact with online communities and leading to cooperative/collaborative learning when their use facilitates sharing common knowledge or problems. Overall e-learning activities are used to allow learners to achieve a learning objective and as mentioned by Bach et al in 
2007, the "e" term has to do more than just use electronic media; it has to promote engagement and enhancement of learning.

Graham et al [4] in 2005 [5], described blended learning using three forms: combining instructional modalities; combining instructional methods and combining online and face to face instruction. Osguthorpe and Graham [6], identified six reasons for applying blended learning in higher education: pedagogical richness; access to knowledge; social interactions; personal agency; cost effectiveness; ease of revision. Also, blended learning allows students to manage their own time as they can go through work material any time in any place building their own pace [7].

Forums are defined as being places of meeting for public discussion. In the context of a learning activity, a forum is a space where a group of people are able to analyse, discuss, and give an opinion in a specific subject. An online discussion forum is an e-learning tool which allows the participation of an online community, where the messages are posted and displayed in a board, giving the opportunity for the participants to access the forum and the posted messages, as often as they want. Participation starts either by contributing to an existing discussion thread on a specific topic or by opening a new discussion. There are basically two types of internet forum, ones that are open for any participant to contribute in an anonymous way and ones where the participants need to register in order to contribute. Forums are also classified as either synchronous, where participants (students) and a moderator (lecturer) participate at the same time in the online discussion, or asynchronous, where the participants and moderator participate in a flexible way in regard to timing, meaning they access the forum at a time when it is convenient for each of them (Bach et al 2007). Independent of the type of forum, each has an administrator and a moderator 
responsible for keeping a friendly environment between participants, eliminating posts if necessary. It must be highlighted that respect is one of the key requirements for a healthy learning network [8].

Another important factor that needs to be considered for a successful learning outcome is "participation" [9]. Group size should be considered in students' participation in an online discussion forum as Kim[9] concluded that participants in classes with small groups opened discussions posted by other participants more frequently and also contributed more to the discussions.

It is important to keep in mind that online discussions might take longer to get started when compared to face to face discussions. To guarantee students' confidence and motivation, more direction from tutors is needed at the beginning, as they are responsible for students' participation and engagement (Bach et al, 2007 [10]). Also it is important to highlight that learner-learner interaction is part of the engagement process [11].

As introduced above, asynchronous forums are part of a blended learning approach. They are used with the purpose of reinforcing face-to-face activities by increasing students' understanding and deepening their knowledge in specific topics. A further advantage of the asynchronous discussion forum (ADF) is the fact that it provides a platform for sharing external resources.

Another way to improve face to face activities and engagement with students is the implementation of flipped classes. In this case students can read reference material, online lessons, etc. before attending the class, giving them the background and enough knowledge to interact in a face-to face activity. Researchers such as Gilboy et al [12] obtained in general 
a $60 \%$ or higher likeability from students in different aspects related to the advantage of participating in flipped classes. However they found limitations as the survey was only focused on student satisfaction regarding the experience.

Ecclestone defined a learning outcome as "being something that a student can do now that they could not do previously...a change in people as a result of a learning experience" [13]. A way of measuring the learning outcomes is by assessing them, representing the benchmark of the quality and the efficiency of what has been taught.

In order to measure the knowledge and the learning outcomes, assessment activities are conducted as part of the learning cycle. The term assessment has been defined by different researchers, and is used synonymously with evaluation, regardless the fact that at times it leads to ambiguity [14].

Challis [15], and Oosterhof et al [16] and Gikandi et al. [14] have established two forms of assessments, summative assessment, which measures the learning outcomes at the end of a course, and formative assessment, which measures the learning that occurs during a course in order to support optimal learning.

Formative assessment gives the opportunity for formative and immediate feedback and engagement with the critical learning process. The learning outcomes in an ADF can be measured by the lecturer by accessing the forum, knowing the number of posts made by each participant and assessing the level of knowledge used in the discussion. The level of participation can be measured by the quality and time spent in the online environment [11]. Students are able to assess their own understanding before posting in any discussion and can assess their own contribution by revisiting the subsequent discussion. Participation is 
fundamental to improving the quality of a discussion, however there are still some doubts regarding of the optimal size group for good interaction [9].

Feedback closes the loop of the learning cycle process. Feedback is used to give information about performance in a specific task and, with this information, future action can be taken. However, feedback needs to be task-specific [17] and it must be highlighted that one of the biggest influences on students' learning is the receipt of feedback once an assessment has been completed. It is not only receiving the mark that is important, but it is receiving quality feedback in a timely manner (at the time the learning process is conducted) that is vital as it is more effective [14].

Finally, in order to further improve the teaching and learning process, lecturers should receive feedback as well as this will help to locate the strengths and the weaknesses of the course. The benefits of a survey are: they help to collect data, information or an opinion; they can be created quickly and administered easily. Some disadvantages of surveys are the limitations of the answers choice provided and poor survey construction. There are common survey question types such as: multiple choice questions; questions that require ranking of a potential answer choice against a scale; and questions where participants are asked if they agree or disagree with a given statement, etc. [18].

It has been noted in spite of the fact that online learning seems to bring many benefits to higher education; there are also barriers to its use that need to be considered. These may be: self-discipline, initiative, time management, computational skills, ability and computer accessibility, to name but a few [4]. 
The implementation of a blended learning, experimental laboratory session for first year undergraduate students in the Department of Mechanical and Aerospace Engineering, was supported by the concepts detailed above and, specifically, ADFs were introduced and used as the main e-learning tool.

\section{Context}

In order to demonstrate principles in materials science for first year undergraduate students in Mechanical and Aerospace Engineering, a compulsory laboratory was developed. The group of one hundred and eighty students was divided into groups of eight, allowing two groups of eight students to attend a one hour laboratory session each week.

A cold rolling process was chosen for the experiment to demonstrate the strain hardening mechanism by studying the influence of cold work on the materials' mechanical properties, namely ductility and hardness.

The material selected for the experiment was a $60 / 40$ brass (60\% copper, $40 \%$ zinc) which was subjected to three reductions in thickness. The one hour session was completely consumed by a 20 -min face-to-face discussion at the start of the experiment, $30 \mathrm{~min}$ of the experiment itself and $10 \mathrm{~min}$ to guide the students on the post laboratory activities which would comprise their technical assessment.

Before attending the laboratory session students were required to go through different online documents containing material related to the rolling milling subject and to take an online quiz. The aim of these activities was to facilitate the required knowledge to interact in the 20 minutes face-to-to face discussion before starting the experiment. In the experiment, students were able to take turns to take samples' dimensions, feed the rolling mill, roll, 
record the results, etc. Finally, as the experiment was concluded, students individually analysed the results and submitted a technical report that included aims and procedure, results and discussion, conclusions and feedback. The feedback that was requested had to include ways to enhance the laboratory session and increase students' knowledge, taking into account that any improvement in the experiment is constrained by both the one hour session lab and a limited budget. The outcomes of the feedback were subsequently analysed.

\section{Experimental laboratory enhancement, development of new scheme}

The initial feedback indicated that at least $90 \%$ of the students would like to have an understanding on how chemical composition and mechanical properties could affect the strain hardening process of materials.

This suggested that the rolling milling laboratory session could be enhanced and the knowledge of the students increased by analysing more materials to be tested. However, noting from previously that the laboratory session could not be extended (and was absolutely limited to a 1 hour session), it was proposed that each group of students analyse a different material, discuss their results and later, conduct a comparison with the results from other groups.

The incorporation of two materials, with different amounts of alloying element, (Brass 60/40 (60\%Cu and $40 \% \mathrm{Zn})$ and 70/30 (70\%Cu and 30\%Zn)) was therefore adopted. This would allow students to increase their knowledge in the area of strain hardening by considering the influence of alloying elements on the mechanical properties of the alloy as well as the influence of cold work on ductility and hardness properties. 
For students to be able to analyse and compare their results, two asynchronous online forums were therefore developed, namely: Group Forum and Experimental Lab Forum.

In the Group Forum, each group of students was provided with space to discuss their own results. The discussion forum was started by posting the results obtained from the practical experimental laboratory session. Students then calculated necessary values from which to develop their own graphs. Each student was required to post at least one discussion and answer one of the discussions posted from another student. Finally, with the most relevant inputs given by each member of the group, the grouped developed a draft of their results and posted them as a discussion in the Experimental Lab Forum.

In the Experimental Lab Forum, each group posted their own final draft of their results and discussion. Students from different group were then able to compare and discuss the results from each of the two materials selected for analysis.

In both forums, the lecturer monitored the participants and the posts by providing orientation and giving guidance towards the results and analysis of the data in order to achieve the aims of the activity. Some examples were checking: the results of calculations; that graphs were properly developed (i.e. that they had a title, that axes were labelled and that units were displayed); that each discussion included a reference; that the results matched theory, etc.

Once the online forums activities were completed, a technical report was submitted and assessed individually. This technical report included descriptions, in the students' own words, of the aims and procedure of the experiment and conclusions drawn by the student based on the discussions in the asynchronous online forums. 
Additional adjustments were subsequently made. In order to enhance the face-to-face discussion prior to the experiment, an online lesson was incorporated. Also the online quiz was moved to the end of the laboratory session activity to more fully assess the students' learning outcomes.

\section{Results and discussion}

The results are divided into four sections:

- Results from a survey conducted before students attended the laboratory session

- Results from students who attended the new scheme (blended activity / incorporation of online forums)

- Results from evaluation of old scheme (traditional) and new scheme (blended)

- Results from students who have become familiar with the use of online discussion forums

\section{Results from a survey conducted before students attended the laboratory session} In order to have an insight into the expertise in ADF of first year students attending the laboratory session, two questions related to participation in online discussion forums and face-to face discussion forums were asked. Figure 1 shows both the questions and the results obtained from a total of 165 students:

From Figure. 1 it is observed that almost 61\% of students had never used online discussion forums before and that almost $79 \%$ of the students already liked to interact in classes, no matter what the group size was. However during the face-to face discussion forum which took place before the experimental session, it was qualitatively observed that spontaneous participation of students was about 30\% (from a group of 8 students) and, through encouragement from the lecturer, the participation increased to $60 \%$. For the remainder of 
the students who didn't participate in the discussion (10\%), examples of the reason for nonparticipation were ascertained to be: lack of confidence as an English speaker; noncompletion of the online lesson activity before attending the laboratory session; didn't want to be exposed by class discussion.

\section{Results from students who attended the new scheme (blended activity / incorporation of online forums)}

The new scheme laboratory is a blended laboratory which includes the experimental session and the online forums for discussion and comparison of results.

The feedback survey was conducted once the experimental activity was concluded and in this case 150 students took part on the activity. Figure 2 shows the questions and results obtained concerning different aspects of the new scheme:

The results show that at least $70 \%$ of the students felt comfortable using the online forums. When analysing the forums it was observed that participation of students was of $90 \%$. They were keen in posting and making comments on others' posts. They interacted between each other and they helped and supported the forum with information they found through their search. Encouraging the students to justify their comments through references seemed to have a positive effect as students were keen to search for very good information, for example in some cases journal papers were used as references.

It is also observed that $70 \%$ of the students benefited from posts made by other participants which helped them clarify their doubts, as reported by Andresen. Overall $88 \%$ of the students were satisfied with what they have learned in the laboratory session under the new scheme (blended activity). This figure (88\%) is very encouraging and has been reflected during discussions held in other laboratory sessions of the same cohort (i.e. car dissection), 
where students have been able to show confidence in their knowledge from the cold rolling topic taught under the new scheme.

Regarding the results related to participation in an online discussion forum or face-to-face forum, it is observed that $11 \%$ of the students prefer to interact in an online discussion forum. This closely matches the result related to participation and interaction in the face-toface discussion forum prior to the experimental session where, as previously mentioned, $10 \%$ of the students didn't participate in the face-to-face forum for different reasons. Unfortunately, due to the anonymous nature of the feedback received, it cannot be known whether this is entirely the same group of students.

Influence of cold work on ductility and hardness was analysed in the Group Forum, however since two groups were established, each of them with a different material (Group 1: 60/40 brass and Group 2: 70/30 brass), they had the opportunity in the Experimental Group Forum (results from each group) to go through a deeper learning approach, as they were able to compare and discuss the influence of chemical composition, material's crystal structure, etc. on cold work, and not just focus on two facts if there was only one material to be analysed (ductility and hardness) [2].

A thread of an online discussion sample related to crack propagation is shown in Figure 3.

\section{Results from evaluation of old scheme (traditional) and new scheme (blended)}

Figure 4 shows some of the questions and the results obtained from a survey conducted with a group of ten students who attended the traditional method (old scheme) and have evaluated the new scheme (blended): 
Analysing Figure 4 , it can be observed that $56 \%$ of the students engaged more with the new scheme laboratory rather than the traditional method (incorporation of flipped class and introduction of ADF), this is in agreement with Gilboy et al [12]. It can be postulated that they have seen an opportunity to increase their knowledge by being able to analyse the behaviour of two different materials under same conditions. The fact that $100 \%$ of the students agree that the online forums are a useful and alternative tool to analyse other results in the laboratory when time is limited categorically endorses their use. However, is through the quality of the posts were authors recognize the deep learning approach taken by the students and how this represented and enhancement in students learning [2].

\section{Results from students who have become familiar with the use of online discussion}

\section{forums}

Figure 5 shows some of the questions and the results obtained from a survey conducted with a group of 132 students who were familiar with the online discussion forums due to their experience in the rolling milling laboratory session and were now attending another laboratory with the same scheme:

When analysing Figure 5 it is observed that $73 \%$ of the students (from 132) felt more comfortable using the online forums having had a previous experience of them. This can be considered to be very encouraging result, especially when it is considered that $61 \%$ (from 165) of the students had never used this e-learning tool before. Also it is observed that $66 \%$ of the students felt that the contributions made in the online forums were worth it and $81 \%$ of the students had benefited from the information posted in the forums, helping them clarify things they didn't understand. 


\section{Example feedback quotations from students}

"I found the online forums to be very useful as they allowed us to discuss results etc. without the complication of finding a time when everyone was free to meet up in person". This is in agreement with previous research (Bach et al [4]).

"Feel very comfortable using forums now. Straightforward to use"

"Found the online forum to be most useful for sharing results and resolving any issues or misunderstandings".

"I think the lab A greatly expanded my knowledge of both metals and crystal structures and in fact encouraged me to look further into the topic which greatly improved the quality of my group's car dissection poster". This is in agreement with Marton and Säljö [2].

“Enjoyed Lab B much more having done Lab A and experienced the forums. Seemed confusing at the start but a good way of learning and interacting with colleagues. Personally I prefer face to face interactions but appreciate that this isn't possible due to time restrictions therefore in this case the forums are useful but they are a new concept to myself and others and take a bit of getting used to" This is in agreement with Andersen [11].

"Personally I found the online forum difficult to use after lab A as I was unsure of what sort of things to post due to never using a discussion forum before. However my opinion of online forums has completely changed after Lab B, the forum was much easier to use as I had a better understanding of what to post"

"I enjoyed both labs and the online forums are easy to use and usefully once you understand how they work and what sort of comments to make in them" 
"Online forums allowed the introduction and analysis of idea's not discussed during the lab thus broadening knowledge in the area"

\section{Observations}

The inclusion of new learning activities involving online tools (i.e. ADFs) gives students flexibility as to when they undertake some of the learning activities, promoting inclusive learning. They also provide the opportunity to enhance and strengthen skills such as cooperative and collaborative learning, critical thinking, analysis and communication, as they are involved in different group activities (face-to-face discussion and online forums) in a blended learning experience [13].

Engaging students in the use of asynchronous forums at early stages of their undergraduate career could encourage the use of forums in future classes and will give them the confidence to pursue future studies through online courses.

From the lecturer's point of view the flipped class (through the implementation of an online lesson in this new scheme) has proven to enhance student interactions. We have also observed how students' engagement and confidence in posting increased during the process. The face-to-face discussion forum is more pro-active when compared to the traditional class (old scheme) and students seem to be more keen to ask questions to expand their knowledge. This result should be studied more deeply by incorporating tools to measure the outcomes of both schemes.

\section{Conclusions}

From the analysis of the quality of the posts uploaded by the students and when comparing with previous experience (traditional, old scheme) the introduction of online asynchronous forums in experimental engineering laboratory classes to facilitate discussion and 
comparison of results from different materials has not only helped students to enhance and expand their knowledge in principles of materials science, but it has also helped to introduce e-learning activities to first year undergraduate students in the Department of Mechanical and Aerospace Engineering.

Providing the opportunity for involvement with online forums at an early stage of a student's undergraduate studies (first year), provides them with the confidence to use them successfully in the future, as it was observed higher confidence along the process.

From the feedback received, it is evident that more than $87 \%$ of the students were satisfied with what they had learned in the blended laboratory session and $80 \%$ of the students agreed that the online asynchronous forums are useful platform to use to compare results and to enhance and increase knowledge when face to face contact time for experimental laboratory activities is restricted.

\section{References}

The authors would like to thank the learning technology team and Dr B. Keating of the University of Strathclyde for the support of this work.

\section{References}

1. Konak A, Clark T and Nasereddin M. Using Kolb's experiential learning cycle to improve student learning in virtual computer laboratories. Comput Educ 2014; 72: 11-22.

2. Marton F and Säljö R. On qualitative differences in learning - I: outcome and process. $B r J$ Educ Psychol 1976; 46: 4-11. 
3. Anon. http://c4lpt.co.uk/directory-of-learning-performance-tools/ (2005, accessed 18 August 2015).

4. Bach Shirley, Haynes Philip and Lewis Smith Jennifer. (2007). “Online Learning and Teaching in Higher Education". Open University Press. McGraw Hill.

5. Graham CR, Allen S and Ure D. Benefits and challenges of blended learning environments. In: Khosrow-Pour M (ed) Encyclopedia of information science and technology. Hershey, PA: Idea Group, 2005, pp.253-259.

6. Osguthorpe RT and Graham CR. Blended learning systems: definitions and directions. $Q$ Rev Dis Educ 2003; 4: 227-234.

7. McKenzie W, Perini E, Rohlf $\mathrm{V}$, et al. A blended learning lecture delivery model for large and diverse undergraduate cohorts. Comput Educ 2013; 64: 116-126.

8. Desanctis G, Fayard AL, Roach M, et al. Learning in online forums. Eur Manag J 2003; 21: $565-577$.

9. Kim J. Influence of group size on students' participation in online discussion forums. Comput Educ 2013; 62: 123-129.

10. Sendra-Portero F, Torales-Chaparro O, Ruiz-Go' mez M, et al. A pilot study to evaluate the use of virtual lectures for undergraduate radiology teaching. Eur J Radiol 2013; 82: 888893.

11. Andresen MA. Asynchronous discussion forums: success factors, outcomes, assessments and limitations. Educ Technol Soc 2009; 12: 249-257. 
12. Gilboy M, Heinerichs S and Pazzaglia G. Enhancing student engagement using the flipped classroom. J Nutr Educ Behav 2015; 47: 109-114.

13. Ecclestone K. Learning outcomes. Sheffield: Centre for Further and Higher Education, Sheffield Hallam University, 1995.

14. Gikandi JW, Morrow D and Davis NE. online formative assessment in higher education: a review of the literature. Comput Educ 2011; 57: 2333-2351.

15. Challis D. Committing to quality learning through adaptive online assessment. Assess Eval High Educ 2005; 30: 519-527.

16. Oosterhof A, Conrad RM and Ely DP. Assessing learners online. New Jersey: Pearson, 2008.

17. Einig S. Supporting students' learning: the use of formative online assessments. Account Educ Int J 2013; 22: 425-444.

18. Analyticstool.com. Survey question types and survey structure web-based survey software, www.analyticstool.com/survey-question-types-and-survey-structure/ (2014).
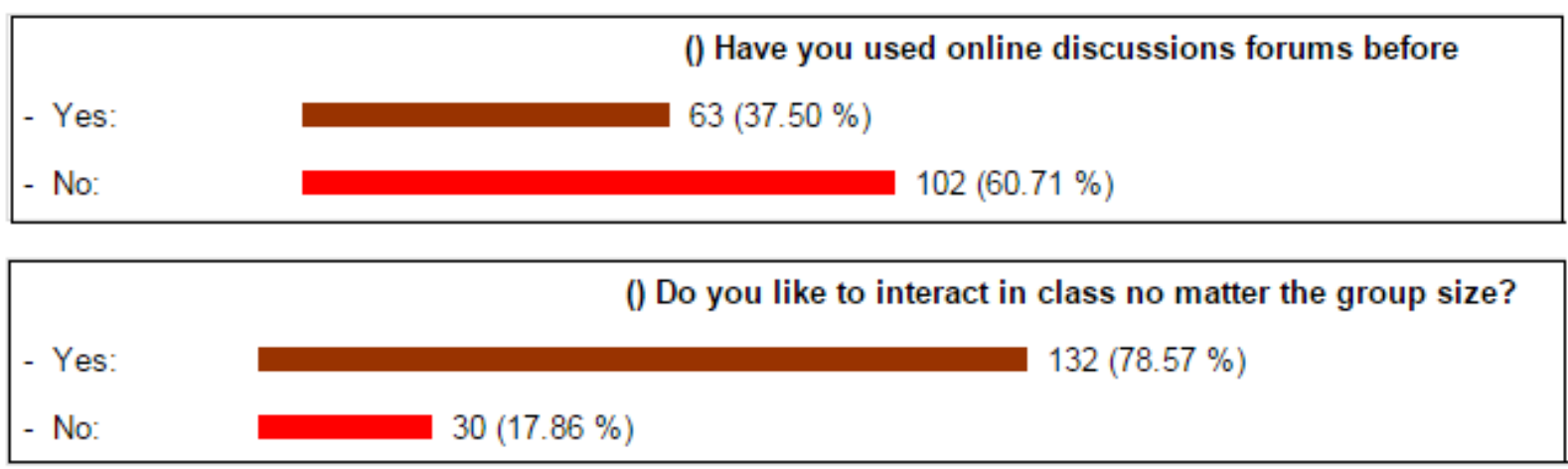

Figure 1. Results of survey conducted before students attended the laboratory session. 

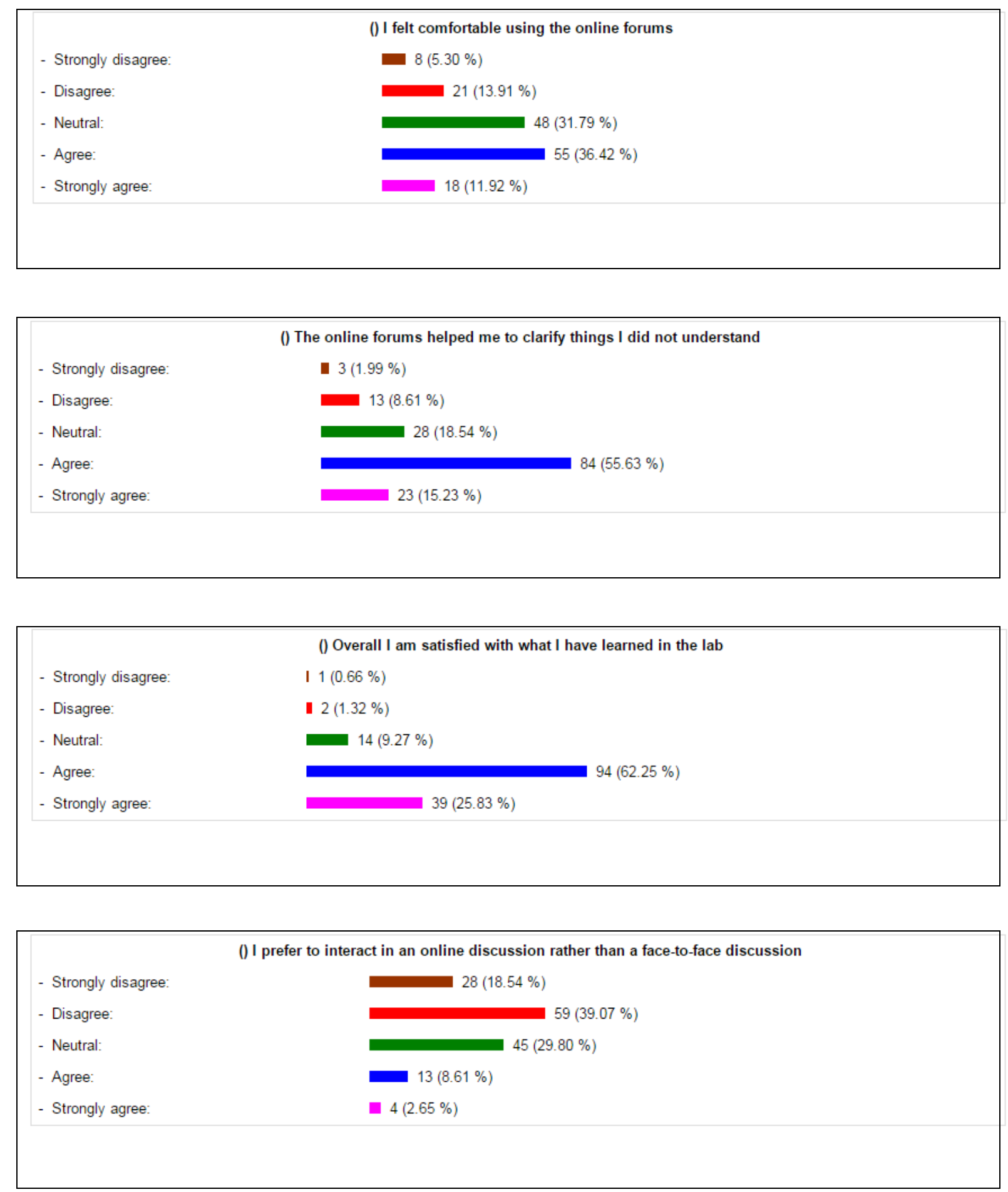

Figure 2. Results on different aspects related to the use of online forums by students who attended the new scheme. 


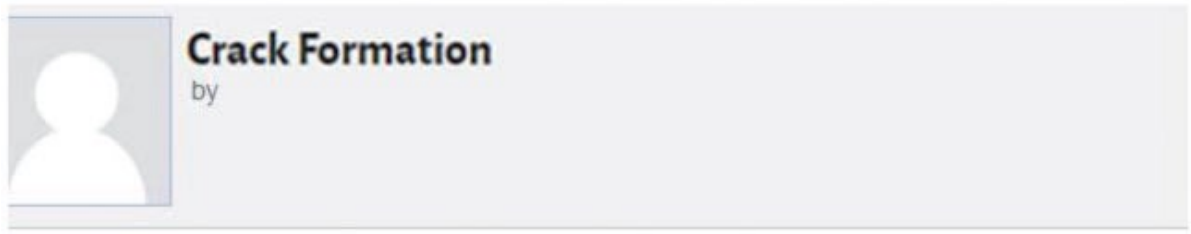

I think the most obvious comparison is the fact $60 / 40$ Brass showed crack formation and $70 / 30$ brass did not. I guess this will come from the amount of zinc in each sample.

"If the zinc content of the brass ranges from $32 \%$ to $39 \%$, it will have increased hot-working abilities but the cold-working will be limited.

If the brass contains over $39 \%$ zinc (example - Muntz Metal), it will have a higher strength and lower ductility (at room temperature)."

source - http///metalsupermarkets.com/blog/difference-between-copper-brass-bronze/

This source shows how $60 / 40$ brass will have a lower ductility compared to the $70 / 30$ brass. Therefore the $60 / 40$ will be able to deform less ie will be less flexible meaning it will crack more easily than the $70 / 30$.

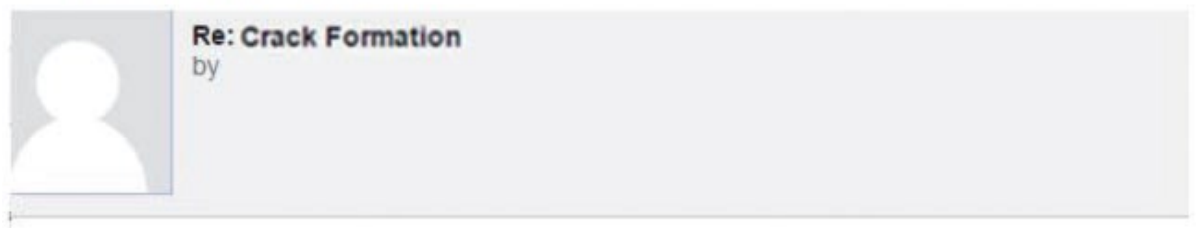

Hi guys I think this might repeat other people but this is what $i$ have.

Compared to the other metal sample the apparent difference is that the $70 / 30$ sample didnt crack. The $70 / 30$ brass would take $70 \%$ cold work to crack. This is because at the original state before any cold rolling was done to either sample the $60 / 40$ brass was much more ductile than the $70 / 30$. This means that from the start it could withstand less stress than the $70 / 30$ to start. Also the grain structure of the metals differ, $60 / 40$ brass has an alpha-beta structure and $70 / 30$ has an alpha structure. As shown in the comparison graph you can see that the alpha-beta structure is stronger, this is due to the fact that the grain size is smaller to start.

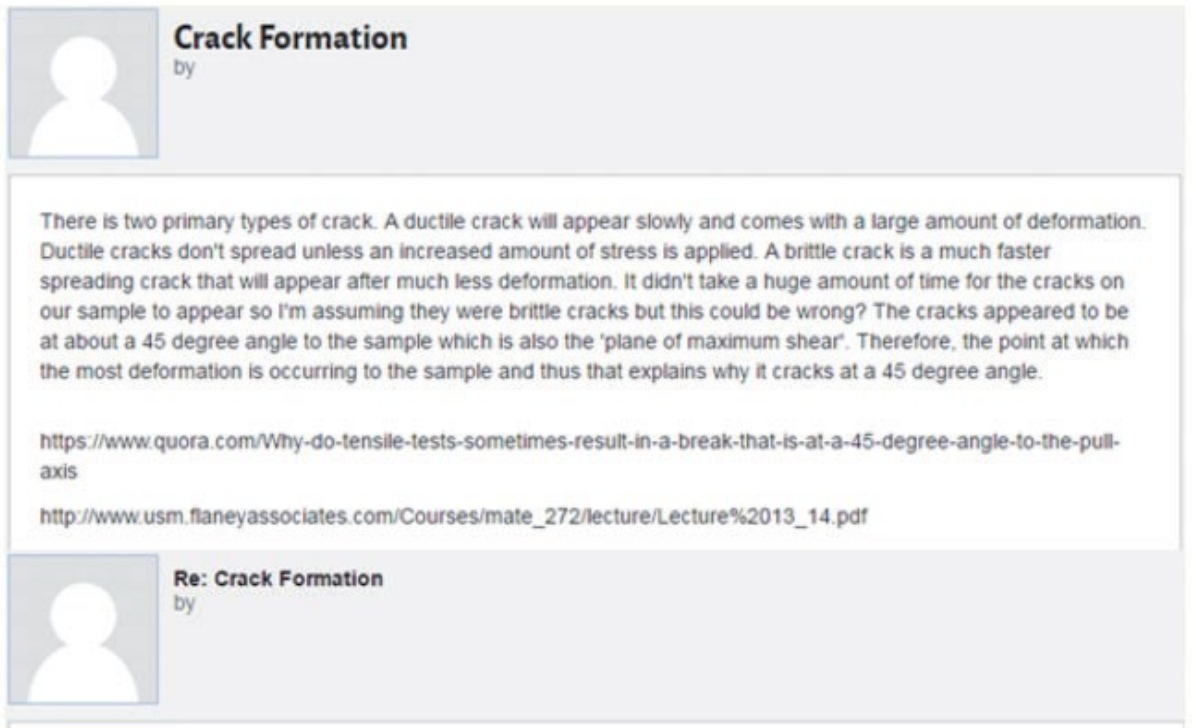

I searched a couple of fracture mechanic documents for ' 45 ' and found something which backs what you said about the plane of maximum shear plane.

http://www.mate. tue. nV-plet/edu/trm/pdt/frmsyl1213. pdt

Figure 3. Example of a thread of an online discussion sample. 


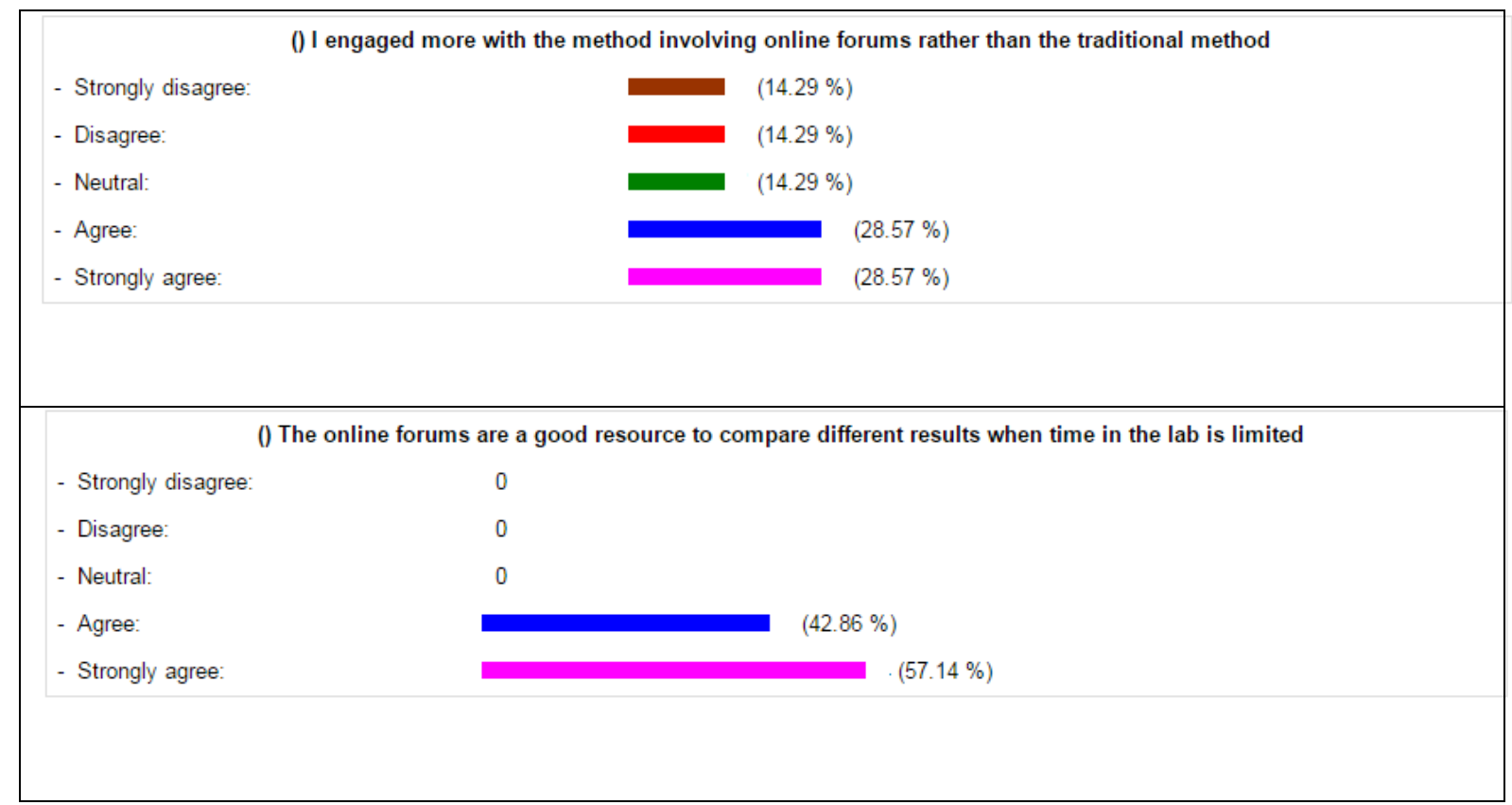

Figure 4. Results obtained from the survey conducted with students who attended the traditional experimental laboratory and evaluated the new scheme laboratory session

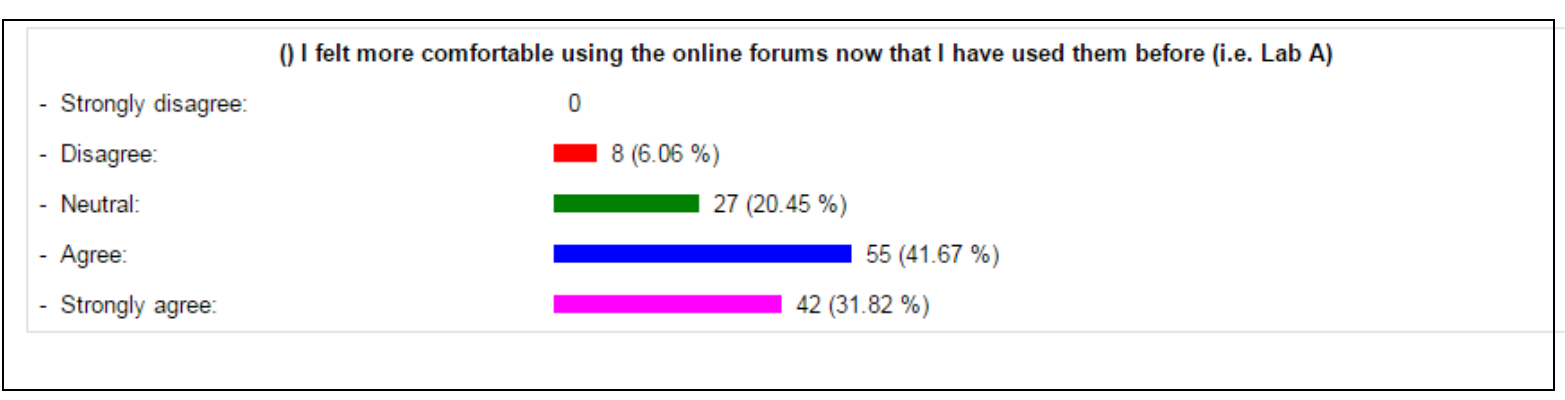

\begin{tabular}{ll|}
\hline & () Contributions in the online forums are not worth it. \\
- Strongly disagree: & $27(20.45 \%)$ \\
- Disagree: & \\
- Neutral: & $14(22.73 \%)$ \\
- Agree: & I $1(0.76 \%)$ \\
- Strongly agree: & \\
\hline
\end{tabular}

() The online forums is an alternative to discuss other results when time in the lab is restricted

- Strongly disagree:
- Disagree:
- Neutral:
- Agree:
- Strongly agree:

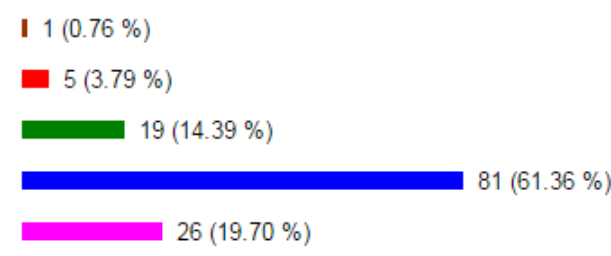


Figure 5. Results obtained from a survey conducted to a group of students that are now familiar to the online discussion forum tool. 